\title{
A serendipitous diagnosis of familial adenomatous polyposis. What next?
}

\author{
Emma Sidebotham*1, Rang Shawis', Chris Taylor ${ }^{2}$, Tan K Chan ${ }^{3}$ and \\ Ewan Mackinnon ${ }^{1}$
}

\begin{abstract}
Address: ${ }^{1}$ Department of Paediatric Surgery and Urology, Sheffield Children's Hospital, Western Bank, Sheffield, S10 2TH, UK, ${ }^{2}$ Department of Paediatric Gastroenterology, Sheffield Children's Hospital, Western Bank, Sheffield, S10 2TH, UK and ${ }^{3}$ Department of Ophthalmology, Sheffield Children's Hospital; Western Bank, Sheffield, S10 2TH, UK

Email: Emma Sidebotham* - emma.sidebotham@sch.nhs.uk

* Corresponding author
\end{abstract}

\author{
from 50th Annual Meeting of the Society for Research into Hydrocephalus and Spina Bifida \\ Cambridge, UK. 30 August - 2 September 2006 \\ Published: 21 December 2006 \\ Cerebrospinal Fluid Research 2006, 3(SuppI I):S52 doi:I0.1186/I743-8454-3-SI-S52
}

(C) 2006 Sidebotham et al; licensee BioMed Central Ltd.

\section{Background}

A seven-year-old boy with shunted hydrocephalus and spina bifida attended eye screening following strabismus surgery. A serendipitous finding of congenital hypertrophy of the retinal-pigmented epithelium (CHRPE) on fundoscopy, led to a diagnosis of probable familial adenomatous polyposis (FAP). Neither parent had any evidence of CHRPE when screened, consistent with a new mutation in the patient. Genetic assessment was undertaken. Bowel screening was deferred till the second decade of life.

One year previously he had undergone a sigmoid colocystoplasty for a high-pressure bladder and recurrent urinary tract infections. Concurrently, a button caecostomy was sited for ACE washouts for faecal soiling.

\section{Materials and methods}

Case Report and Literature Review

\section{Results}

\section{Evolution of clinical history}

Bladder catheterisation was satisfactory but intractable problems with bowel management fortuitously led to further evaluation at age eight years. Inflammatory markers were found to be raised. Upper and lower gastrointestinal endoscopy were undertaken even though bowel mucosal involvement from FAP would not be expected at this age. Numerous $(>100)$ sessile polyps were found throughout the colon. Colectomy was undertaken to prevent inevitable long-term malignant transformation in the large intestine.

\section{Conclusion \\ The Dilemma}

This boy, now 9 years of age, requires lifelong surveillance for malignant change in the rectal stump and proximal gastrointestinal tract.

The dilemma is to foresee the eventual outcome of his cystoplasty. Augmentation is postulated to increase the risk of malignant change in the bladder. FAP produces a field change in the bowel mucosa predisposing to malignant change and there have been case reports of transitional cell carcinoma of the bladder in FAP. Should the colonic augmentation be removed? 